\title{
Endometrial Sampling for Endometrial Cancer: Still the Gold Standard?
}

\author{
Bamidele Johnson Alegbeleye* \\ *Department of Surgery, St Elizabeth Catholic General Hospital, Cameroon \\ *Corresponding author: Bamidele Johnson Alegbeleye, Department of Surgery, St Elizabeth Catholic General Hospital, Shisong, P.0 \\ Box 8, Kumbo-Nso, Northwestern Region, Cameroon.
}

To Cite This Article: Bamidele Johnson Alegbeleye. Endometrial Sampling for Endometrial Cancer: Still the Gold Standard?. Am J Biomed Sci \& Res. 2019 - 2(3). AJBSR.MS.ID.000585. DOI: 10.34297/AJBSR.2019.02.000585

Received: April 04, 2019 | Published: April 08, 2019

\section{Endometrial Cancer (EC)}

Is the most common gynaecological malignancy affecting women in developed countries and the second most common gynaecological malignancy world-wide, due to the higher rates of cervical cancer in the developing world [1]. The incidence of EC is steadily increasing, largely owing to an ageing population and escalating rates of obesity [2]. According to International Federation of Gynecology and Obstetrics (FIGO), EC is a major differential diagnosis of AUB in the reproductive women [3]. Despite the frequency of this disease, awareness amongst the general population is low and EC research is somewhat underfunded relative to its societal burden [4].

In the past, multiple attempts to evaluate the histological grade preoperatively were without significant success [5,6]. Dilation and curettage (D\&C) were once the gold standard for endometria sampling and routinely used with an upgrade rate of $17-26 \%$, compared to the final pathology [7-9]. In an attempt to develop a less invasive diagnostic method, office endometrial sampling became progressively popular. However, studies aimed at investigating office biopsies revealed an apparent inaccuracy in histological grading with an upgrade rate of nearly $30-50 \%$, compared to hysterectomy pathology [10]. Cotillo et al. [11] investigated the accuracy of transcervical resectoscope (TCR) and revealed a rather optimistic finding of $97.1 \%$ correlation with the final pathology.

This could be a solution to overcome the hurdle of inevitable upgrades. This method allows direct visualization, a targeted biopsy, and theoretically a more accurate evaluation of preoperative tumour grading [11]. There is also recent progress with effort at improving the diagnostic accuracy of endometrial cancer through immunohistochemistry biomarkers targeting endometrial hyperplasia and predicting progression of endometrial hyperplasia to endometrial cancer [12]. There is need for the clinician to consider therefore the possibility of ECs when treating an abnormal uterine bleeding.

Furthermore, we experienced a case scenario where a colleague had multiple endometrial sampling done and each sample sent to different pathologist and the outcome of the histopathology reports was bizarre. The results were that of different reports establishing the inconsistencies associated with endometrial sampling for endometrial cancer. Similar, encounters have been reported in literature which is the bane of this editorial report. The great question we need an urgent answer for remains "is endometrial sampling for endometrial cancer still the gold standard?"

\section{Abnormal Uterine Bleeding (AUB)}

May be defined as any variation from the normal menstrual cycle related to reproductive status; as well as other bleeding not related to menses provides the terminology and descriptions are consistent with the FIGO Menstrual Disorders Working Group consensus statement $[13,14]$. AUB is the direct cause of a significant health care burden for women, their families, and society as a whole. Up to $30 \%$ of women will seek medical assistance for this problem during their reproductive years [15-17]. Patients with AUB are at risk for endometrial carcinoma and therefore AUB warrants further investigation [18]. Histological endometrial assessment is indicated when a patient presents with AUB and an increased endometrial thickness on transvaginal sonography (TVS) [19,20]. Outpatient endometrial biopsy is the least invasive technique to obtain tissue for histological assessment. Endometrial biopsies have a very high sensitivity for diagnosing an endometrial (pre)malignancy in AUB women (95\%) [21].

Furthermore, performing an endometrial biopsy in women with AUB with increased endometrial thickness is the most cost-effective strategy [22]. Yet, 7-68\% of outpatient endometrial biopsy samples are inconclusive because the amount of tissue obtained is insufficient for a reliable histopathological diagnosis [22-25]. In such cases, a more invasive hysteroscopy or dilatation and curettage (D\&C) is necessary in order to rule out endometrial carcinoma or atypical hyperplasia, which is present in $6 \%$ of these women [23]. The high failure rate due to inconclusive endometrial biopsies might affect the cost-effectiveness of the diagnostic work-up. 
Reports from the literature suggest that the attempts to increase the diagnostic efficiency of outpatient endometrial biopsy by structured assessment have not yielded significant improvement in outcome. Therefore, these women cannot be reassured without further invasive, diagnostics [23]. Reviewing hospital protocols revealed that standardized sampling methods was not available in most hospitals, let alone the recommendations on using a tenaculum, entering the uterine cavity more than once, or the use of analgesia in painful procedures. In the cost-effectiveness analysis by Clark et al, the failure rate due to inconclusive endometrial biopsy samples was $12 \%$ (95\% CI 0.09-0.15) based on a systematic review $[22,23]$. Other studies reported a failure rate of 7-68\% [22-25].

\section{The Clinical Importance of a Diagnosis of Endometrial Hyperplasia (EH)}

relates to the long-term risk of progression to endometrioid EC and it is generally accepted that cytological atypia is the principal histological characteristic when assessing EHs for malignant potential [26]. However, not all EHs will progress to malignancy; some EHs occur secondary to estrogenic proliferation without an underlying malignant mechanism. These patients may be asymptomatic and, in some cases, the EH may regress without ever being detected. Several histological classification methods have been proposed aiming to correlate $\mathrm{EH}$ architecture and cytological features with the risk of progression to endometrioid EC [27].

The two prominent classification systems are

a. The World Health Organization (WHO) system, established in 1994 with revision in 2003, which is widely known within current clinical gynaecological practice and

b. The endometrial intraepithelial neoplasia (EIN) system, introduced in 2000 [28] and was endorsed in 2014 by the WHO as part of their most recent classification of tumours of the female reproductive organs [29].

\section{The Endometrial Intraepithelial Neoplasia (EIN)}

Classification system divides hyperplastic endometrial lesions into two groups:

\section{a. Benign $\mathrm{EH}$ and}

b. EIN. This is based on objective diagnostic criteria that can be determined from a haematoxylin and eosin (H\&E) stained endometrial section.

These criteria emulate what the D-score achieves; however, they can be ascertained quickly by a pathologist using routine light microscopy [30]. EIN lesions are defined as monoclonal proliferations of architecturally and cytologically altered premalignant endometrial glands, which are prone to transformation to endometrioid EC [28].

\section{Conclusion}

It is mandatory for clinicians assessing AUB to recognize this disease entity as a possible differential diagnosis. Reports from literature corroborate the fact that there is a high risk of missed diagnosis with less invasive pre-operative diagnostic method of office endometrial trial sampling. The new progress in search of immunohistochemical biomarkers may eventually lay to rest the inconsistent histopathology reports for endometrial biopsy in the nearest future.

\section{References}

1. Ferlay J, Soerjomataram I, Dikshit R, Eser S, Mathers C, et al. (2015) Cancer incidence and mortality worldwide: sources, methods and major patterns in GLOBOCAN 2012. Int J Cancer 136(5): E359-E386.

2. Renehan AG, Soerjomataram I, Tyson M, Egger M, Zwahlen M, et al. (2010) Incident cancer burden attributable to excess body mass index in 30 European countries. Int J Cancer 126: 692-702.

3. Singh S, Best C, Dunn S, Leyland N, Wolfman LW, et al. (2013) Abnormal Uterine Bleeding in Pre-Menopausal Women. Journal OG Can 35(5): 473-475.

4. Carter AJR, Nguyen CN (2012) A comparison of cancer burden and research spending reveals discrepancies in the distribution of research funding. BMC Public Health 12: 526.

5. Shepherd JH (1989) Revised FIGO staging for gynaecological cancer. Br J Obstet Gynaecol 96: 889-892.

6. Mariani A, Dowdy SC, Cliby WA, Gostout BS, Jones MB, et al. (2008) Prospective assessment of lymphatic dissemination in endometrial cancer: a paradigm shifts in surgical staging. Gynecol Oncol 109: 11-18.

7. Leitao MM, Kehoe S, Barakat RR, Alektiar K, Gattoc LP, et al. (2009) Comparison of D\&C and office endometrial biopsy accuracy in patients with FIGO grade 1 endometrial adenocarcinoma. Gynecol Oncol 113: 105-108.

8. Larson DM, Johnson KK, Broste SK, Krawisz BR, Kresl JJ (1995) Comparison of D\&C and office endometrial biopsy in predicting final histopathologic grade in endo-metrial cancer. Obstet Gynecol 86(1): 3842.

9. Frumovitz M, Singh DK, Meyer L, Smith DH, Wertheim I, et al. (2004) Predictors of final histology in patients with endometrial cancer. Gynecol Oncol 95(3): 463-468.

10. Eltabbakh GH, Shamonki J, Mount SL (2005) Surgical stage, final grade, and survival of women with endometrial carcinoma whose preoperative endometrial biopsy shows well-differentiated tumors. Gynecol Oncol 99(2): 309-312.

11. Cutillo G, Cignini P, Visca P, Vizza E, Sbiroli C (2007) Endometrial biopsy by means of the hysteroscopic resectoscope for the evaluation of tumor differentiation in endometrial cancer: a pilot study. Eur J Surg Oncol 33(7): 907-910.

12. Sanderson PA, Critchley HOD, Alistair RW, Williams ARW, et al. (2017) Human Reproduction Update. 23(2): 232-254.

13. Edlund M, Blomback M, von Schoultz B, Andersson O (1996) On the value of menorrhagia as a predictor for coagulation disorders. Am J Hematol 53: 234-238.

14. Dilley A, Drews C, Miller C, Lally C, Austin H, et al. (2001) Von Willebrand disease and other inherited bleeding disorders among women diagnosed with menorrhagia. Obstet Gynecol 97(4): 630-636.

15. Kjerulff KH, Erickson BA, Langenberg PW (1996) Chronic gynaecological conditions reported by US women: findings from the national health interview survey, 1984 to 1992. Am J Public Health 86(2): 195-199.

16. Market Opinion and Research International (MORI). (1990) Women's health in 1990. London: MORI.

17. Barnard K, Frayne SM, Skinner KM, Sullivan LM (2003) Health status among women with menstrual symptoms. J Womens Health (Larchmt) 12(9): 911-919.

18. Breijer MC, Visser NCM, VanHanegem N, van der Wurff AA, Opmeer BC, et al. (2016) Structured Assessment to Decrease the Amount of 
Inconclusive Endometrial Biopsies in Women with Postmenopausal Bleeding. Int J Surg Oncol p. 5.

19. American College of Obstetricians and Gynaecologists (2009) ACOG Committee Opinion No. 426: the role of transvaginal ultrasonography in the evaluation of postmenopausal bleeding. Obstet Gynecol 113(2): 462-464.

20. Dutch Society of Obstetrics and Gynaecology (NVOG) (2003) NVOGRichtlijn Abnormaal Vaginaal Bloedverlies in de Menopauze.

21. Dijkhuizen FPHLJ, Brolmann HAM, Potters AE, Bongers MY, Heintz APM (1996) The accuracy of transvaginal ultrasonography in the diagnosis of endometrial abnormalities, Obstetrics and Gynaecology, 87(3): 345349.

22. Clark TJ, Mann CH, Shah N, Khan KS, Song F, et al. (2002) Accuracy of outpatient endometrial biopsy in the diagnosis of endometrial cancer: a systematic quantitative review, BJOG 109(3): 313-321.

23. van Doorn HC, BC Opmeer, Burger CW, Duk MJ, Kooi GS, et al. (2007) Inadequate office endometrial sample requires further evaluation in women with postmenopausal bleeding and abnormal ultrasound results, Int J Gynaecol Obstet 99(2): 100-104.

24. Gordon SJ, Westgate J (1999) The incidence and management of failed Pipelle sampling in a general outpatient clinic. Aust N Z J Obstet Gynaecol 39(1): 115-118.
25. Williams ARW, Brechin S, PorterAJL, Warner P, Critchley HO (2008) Factors affecting adequacy of Pipelle and Tao Brush endometrial sampling, BJOG 115(8): 1028-1036.

26. Ellenson LH, Ronnett BM, Kurman RJ (2011) Precursor lesions of endometrial carcinoma. Kurman RJ, Ellenson LH, Ronnett BM (Eds). Blaustein's Pathology of the Female Genital Tract. Boston MA: Springer 359-392.

27. Chandra V, Kim JJ, Benbrook DM, Dwivedi A, Rai R (2016) Therapeutic options for management of endometrial hyperplasia. J Gynecol Oncol 27: 712-749.

28. Mutter GL (2000) Endometrial intraepithelial neoplasia (EIN): will it bring order to chaos? The Endometrial Collaborative Group. Gynecol Oncol 76(3): 287-290.

29. Kurman R, Carcangiu M, Herrington C, Young R (2014) World Health Organization Classification of Tumours of Female Reproductive Organs, 4th Edn. Lyon France: International Agency for Research on Cancer (IARC) Press.

30. Owings RA, Quick CM (2014) Endometrial intraepithelial neoplasia. Arch Pathol Lab Med 138: 484-491. 